\title{
Acute Poisoning in Children: Data of a Tertiary Care Unit
}

ISSN: 2576-9200

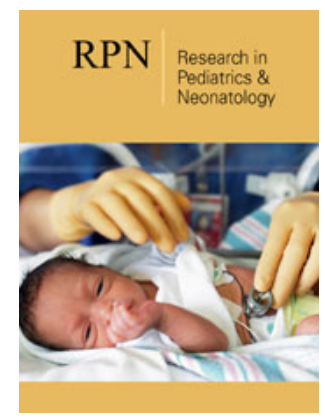

*Corresponding author: Keerthidarshini k, Department of Pediatrics, Shri BM Patil Medical college, Vijayapur, India

Submission: 幽 December 03, 2019

Published: 非 January 06, 2020

Volume 4 - Issue 2

How to cite this article: Keerthidarshini k, Kalyanshettar S, lakhkar B, ,RH Gobbur, AS Akki, MM Patil and Patil SV. Acute Poisoning in Children: Data of a Tertiary Care Unit. Res Pediatr Neonatol. 4(2). RPN.000581.2020.

DOI: 10.31031/RPN.2020.04.000581

Copyright $₫$ Keerthidarshini $\mathrm{k}$

This article is distributed under the terms of the Creative Commons Attribution 4.0 International License, which permits unrestricted use and redistribution provided that the original author and source are credited.

\author{
Keerthidarshini k*, Kalyanshettar SS, lakhkar B ,RH Gobbur, AS Akki, MM \\ Patil and Patil SV \\ Department of Pediatrics, India
}

\section{Introduction}

Children are curious and explore their world with all their senses, including taste. As a result, the home and its surroundings can be a dangerous place when poisonous substances are inadvertently ingested. Poisoning in pediatric patients is a common and preventable cause of morbidity and mortality. Incidence of childhood poisoning in India is $0.23-3.3 \%$. 50-90\% of all childhood poisoning cases are between 1-5yrs age group and mortality rate is $3-5 \%$ and males outnumber females and mainly are due to accidental consumption. Suicidal poisoning is common after 13years of age and is due to household chemicals and drugs. Profile and outcome of poisoned patients in a given region is influenced by the social, economic and cultural practices prevalent and also by the availability and the quality of the medical facilities. With this background we conducted this study in the department of Pediatrics of Shri B. M. Patil Medical College hospital and research Centre, Vijayapura.

\section{Material and Methods}

\section{Study type \\ Cross sectional retrospective study.}

\section{Study period: August 2016-August 2017}

In this study 39 children under 15 years of age presenting with signs and symptoms of poisoning to Paediatric ICU of shri. B. M. Patil medical college hospital and research centre, Vijayapur were included. Children were assessed for poisoning with drugs, hydrocarbons, bathroom detergents, and plants based on the history and were managed according to standard protocols. Stomach contents were sent for forensic analysis except kerosene and other poisonings where stomach wash is contraindicated. Ethical clearance was taken from institutional ethical clearance committee.

\section{Results}

Total no. of participants was 39.

\section{Discussion}

Out of the 39 cases included in our study incidence was more common among males (53.8\%) and $46.2 \%$ were females. This was similar to the study conducted in Mangalore by Ramesh KN et al. [1] which showed $75.4 \%$ of the poisoning cases were in males. Another study by Maharani BN et al. [2] also revealed the similar results. In our study majority of the poisonings belonged to the age group of 1-5 years with $41 \%$ representation, this was mostly accidental consumption, followed by 10-15 years most of which were intentional consumptions. Maximum cases of poisoning were due to hydrocarbons (28.2\%), followed by organophosphorus (25.6\%) and castor seed poisoning (20.5\%) (Table 1-5). This was on par with the study conducted in North India by Utkarsh Kohli et al. [3] which showed kerosene (28\%) as most common cause of poisoning in childhood followed by insecticides with $12 \%$ (Figure $1 \& 2$ ). Analysis of outcome in our study showed that $97.4 \%$ of them were discharged and $2.6 \%$ of them died, which was in line with other studies by Utkarsh et al. [3]. 


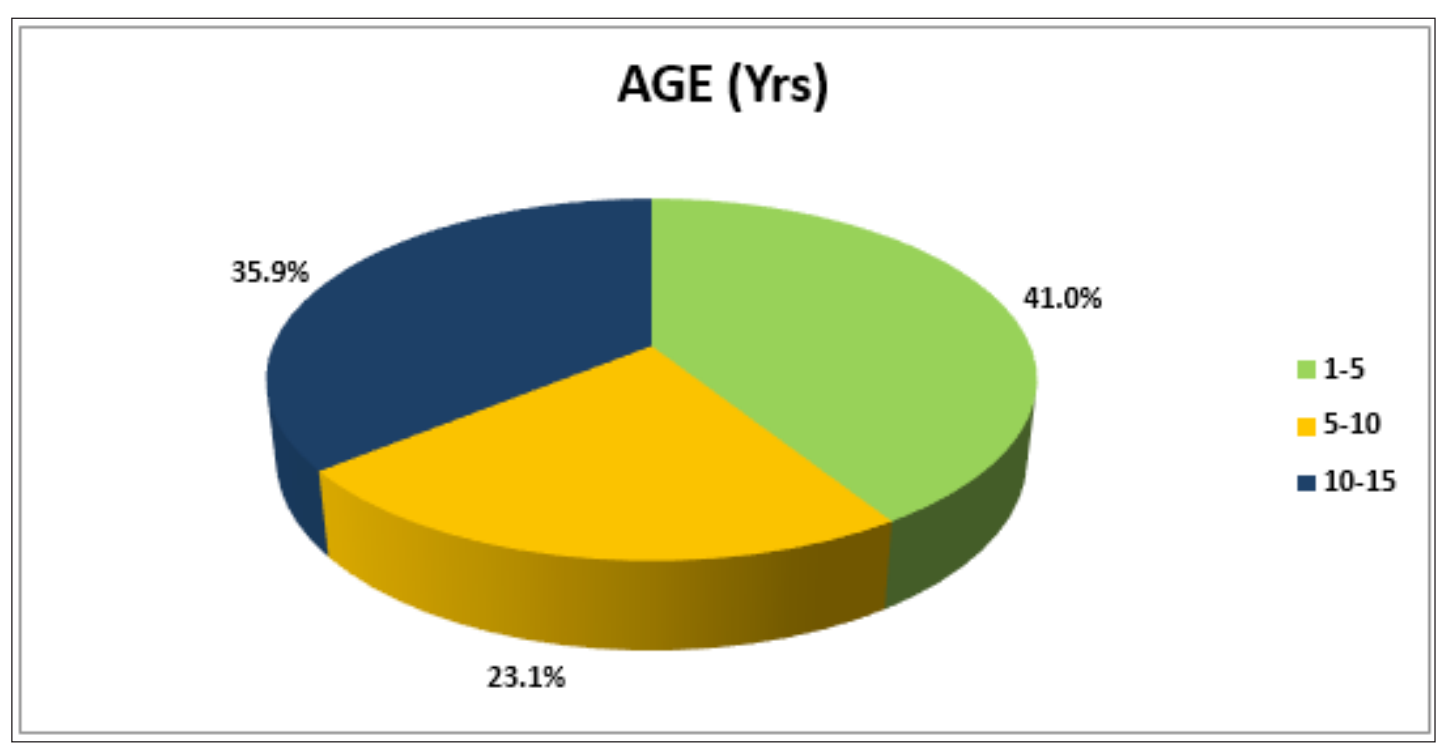

Figure 1. Age distribution of study participants. Mean Age is $6.6 \pm 4.7 \mathrm{yrs}$.

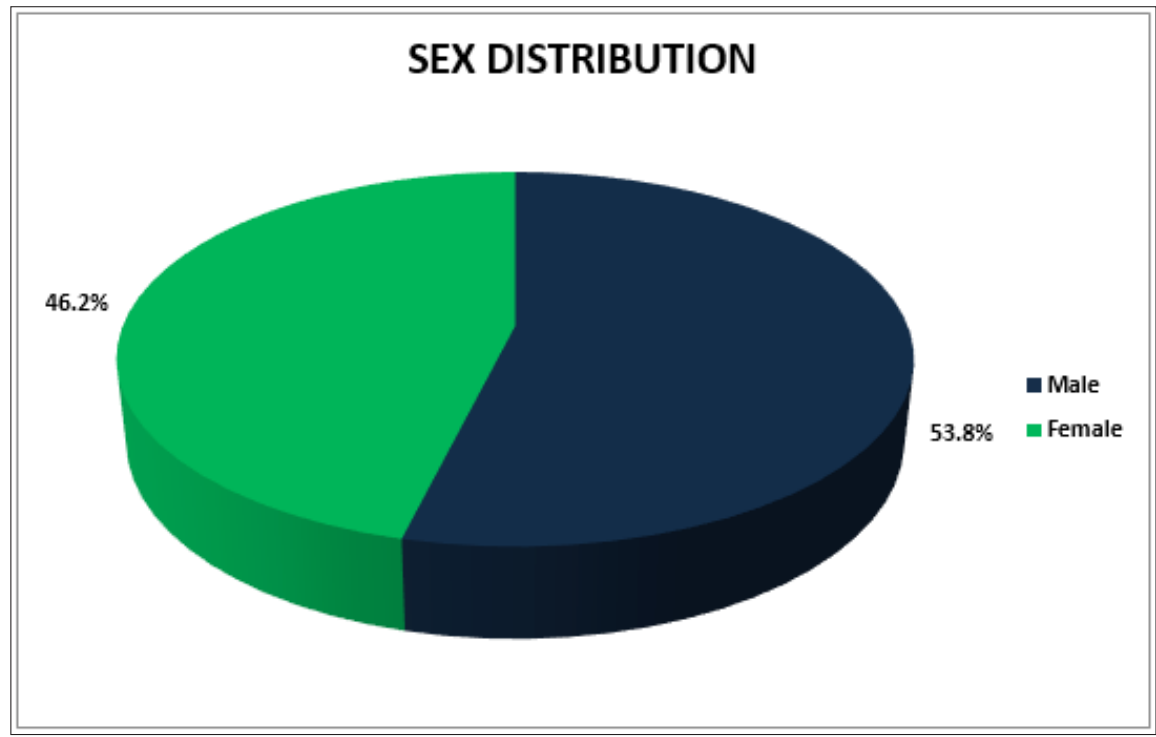

Figure 2. Sex Distribution of study participants.

Table 1: Types of poisoning seen in the study participants.

\begin{tabular}{|c|c|c|}
\hline Poisoning & N & Percent \\
\hline Hydrocarbon & 11 & 28.2 \\
\hline Organophosphorus & 10 & 25.6 \\
\hline Castor seed & 8 & 20.5 \\
\hline Pyrethroid & 3 & 7.7 \\
\hline Food poisoning & 2 & 5.1 \\
\hline Phenol & 2 & 5.1 \\
\hline Benzodiazepine & 1 & 2.6 \\
\hline Datura & 1 & 2.6 \\
\hline Unknown & 1 & 2.6 \\
\hline Total & 39 & 100 \\
\hline
\end{tabular}


Table 2: Distribution of types of poisoning with gender of the study participants.

\begin{tabular}{|c|c|c|c|c|}
\hline \multirow{2}{*}{ Poisoning } & \multicolumn{2}{|c|}{ Male } & \multicolumn{2}{|c|}{ Female } \\
\cline { 2 - 5 } & $\mathbf{N}$ & $\mathbf{0}$ & $\mathbf{N}$ & 5.6 \\
\hline Benzodiazepine & 0 & 0 & 4 & 22.2 \\
\hline Castor seed & 4 & 19 & 0 & 0 \\
\hline Datura & 1 & 4.8 & 0 & 22.2 \\
\hline Food poisoning & 2 & 9.5 & 4 & 27.8 \\
\hline Hydrocarbon & 7 & 33.3 & 5 & 11.1 \\
\hline Organophosphorus & 5 & 23.8 & 2 & 11.1 \\
\hline Phenol & 0 & 0 & 2 & 0 \\
\hline Pyrethroid & 1 & 4.8 & 0 & 100 \\
\hline Unknown & 1 & 4.8 & 10 & 0 \\
\hline
\end{tabular}

Table 3: Distribution of types of poisoning by age of the study participants.

\begin{tabular}{|c|c|c|c|c|c|c|c|}
\hline Age (Yrs.) & \multicolumn{2}{|c|}{ 01-May } & \multicolumn{2}{|c|}{ 05-0ct } & \multicolumn{2}{|c|}{ Oct-15 } & \multirow{2}{*}{$P$ value } \\
\hline Poisoning & $\mathbf{N}$ & $\%$ & $\mathbf{N}$ & $\%$ & $\mathbf{N}$ & $\%$ & \\
\hline Benzodiazepine & 0 & 0 & 0 & 0 & 1 & 7.1 & \multirow{10}{*}{0.148} \\
\hline Castor seed & 2 & 12.5 & 6 & 66.7 & 0 & 0 & \\
\hline Datura & 0 & 0 & 1 & 11.1 & 0 & 0 & \\
\hline Food poisoning & 1 & 6.3 & 1 & 11.1 & 0 & 0 & \\
\hline Hydrocarbon & 10 & 62.5 & 0 & 0 & 1 & 7.1 & \\
\hline Organophosphorus & 2 & 12.5 & 1 & 11.1 & 7 & 50 & \\
\hline Phenol & 0 & 0 & 0 & 0 & 2 & 14.3 & \\
\hline Pyrethroid & 1 & 6.3 & 0 & 0 & 2 & 14.3 & \\
\hline Unknown & 0 & 0 & 0 & 0 & 1 & 7.1 & \\
\hline Total & 16 & 100 & 9 & 100 & 14 & 100 & \\
\hline
\end{tabular}

Table 4: Outcome of the course of poisoning.

\begin{tabular}{|c|c|c|}
\hline Result & N & Percent \\
\hline Death & 1 & bbb2.6 \\
\hline Discharge & 38 & 97.4 \\
\hline Sequelae & 0 & 0 \\
\hline
\end{tabular}

Table 5: Distribution of outcome of the poisoning with age of the study participants.

\begin{tabular}{|c|c|c|c|c|c|c|}
\hline \multirow{2}{*}{ Age (Yrs.) } & \multicolumn{3}{|c|}{ 01-May } & \multicolumn{2}{c|}{ 05-Oct } & \multicolumn{2}{c|}{ Oct-15 } \\
\hline Outcome & N & \% & N & \% & N & P value \\
\hline Death & 0 & 0 & 1 & 11.1 & 0 & 0 \\
\hline Discharge & 16 & 100 & 8 & 88.9 & 14 & 100 \\
\hline Total & 16 & 100 & 9 & 100 & 14 & 100 \\
\hline
\end{tabular}

\section{Conclusion}

Young children are particularly susceptible to accidental ingestion of poisons, hence,
1. Removing the poisoning agent from the environment.

2. Educating parents and proper guidance to parents. 
3. Legislation of child-resistant packaging of necessary poisonous agents.

4. Establishing a poison control centre to triage poisonings.

5. Dispensing accurate and timely advice to caregivers and health facilities, directing first aid when appropriate, and

6. Referring early more severe poisonings to treatment at higher health facility.

Since adolescents are more prone for accidental consumption of poison, need for adolescent education, proper counselling and hence, the need for "Adolescent clinic" [4].

\section{References}

1. Ramesh KN, Rao KB, Kumar GS (2009) Pattern and outcome of acute poisoning cases in a tertiary care hospital, Karnataka, India. Indian J Crit Care Med 13(3): 152-155.

2. Maharani B, Vijayakumari N (2013) Profile of poisoning cases in a tertiary care hospital, Tamil Nadu, India. J App Pharm Sci 3(01): 91-94.

3. Kholi U, Kuttiat VS, Lodha R, Kabra SK (2008) Profile of childhood poisoning at tertiary care center in North India. Indian J of Pediatrics 75: 791-794.

4. Children Poisoning. World report on child injury prevention. UNICEF. World Health Organization. 